\title{
Indicador de governança corporativa para as empresas nacionais da BM\&FBOVESPA
}

Este trabalho propõe a construção de um indicador para a avaliação das práticas de governança corporativa adotadas por uma amostra de 193 empresas da BM\&FBOVESPA, considerando as informações sobre capital social e cronograma de eventos corporativos disponibilizadas no site da Bm\&FBovespa. Foi utilizada a técnica estatística multivariada de Análise de Componentes Principais - ACP, adotando-se o procedimento proposto por Nagar et al. (2002), que utilizam somente as componentes principais que explicam a maior parte da variabilidade dos dados amostrais, considerando os autovalores maiores ou iguais a um. Os resultados mostraram a coerência do IGC proposto, uma vez que a maioria das empresas com níveis de governança corporativa mais próximos de 1, de fato, figuram entre as empresas certificadas pela Bm\&FBovespa como sendo de Novo Mercado em conformidade com os Níveis Diferenciados de Governança Corporativa.

Palavras-chave: Governança Corporativa; Indicador; Empresas; ACP.

\section{Corporate governance indicator for BM\&FBOVESPA national companies}

\begin{abstract}
This paper proposes the construction of an indicator for the evaluation of corporate governance practices adopted by a sample of 193 BM \& FBOVESPA companies, considering the information on share capital and corporate event schedule available on the Bm\&FBovespa website. The multivariate statistical technique of Principal Component Analysis - PCA was used, adopting the procedure proposed by Nagar et al. (2002), who use only the principal components that explain most of the variability of the sample data, considering the eigenvalues ??greater than or equal to one. The results showed the consistency of the proposed IGC, since most companies with corporate governance levels closer to 1, in fact, are among the companies certified by Bm\&FBovespa as New Market in accordance with the Differentiated Levels of Corporate Governance.
\end{abstract}

Keywords: Corporate governance; Indicator; Companies; ACP.

Topic: Finanças Empresariais

Reviewed anonymously in the process of blind peer.
Received: 05/07/2019

Approved: 07/09/2019
Ailton Corecha de Souza (iD)

Universidade da Amazônia, Brasil

http://lattes.cnpq.br/9068773737623749

http://orcid.org/0000-0001-5604-6583

ailton.corecha@gmail.com

Igor de Jesus Lobato Pompeu Gammarano (iD)

Universidade da Amazônia, Brasil

http://lattes.cnpq.br/9283837802352464

http://orcid.org/0000-0001-7769-8265

igor.internacionalista@gmail.com

Cyntia Meireles Martins (it

Universidade da Amazônia, Brasil

http://lattes.cnpq.br/6299203737952237

http://orcid.org/0000-0002-5695-8504

cyntiamei@hotmail.com

\author{
Sérgio Castro Gomes (iD \\ Universidade da Amazônia, Brasil \\ http://lattes.cnpq.br/6378345461837988 \\ http://orcid.org/0000-0002-1731-8766 \\ sergio.gomes@unama.br
}

Referencing this:

SOUZA, A. C.; GAMMARANO, I. J. L. P.; MARTINS, C. M.; GOMES, S. C. Indicador de governança corporativa para as empresas nacionais da BM\&FBOVESPA. Revista Brasileira de Administração Científica, v.10, n.3, p.21-37, 2019. DOI: http://doi.org/10.6008/CBPC2179$\underline{684 X .2019 .003 .0003}$ 


\section{INTRODUÇÃO}

Diante do cenário atual mundialmente globalizado, onde boa parte das organizações está enfrentando crises políticas, crises econômico-financeiras, escassez de recursos, mudanças e incertezas, torna-se importante a adoção de boas práticas de governança corporativa (MOURA et al., 2016) que proporcionem criação de valor.

Diante disso, a governança corporativa visa equilibrar o conflito de interesses entre gestores e investidores de tal forma que não comprometam a organização por ações tendenciosas, o que prejudicaria o bom andamento da empresa (MACMILLAN et al., 2001). Com a governança devidamente tratada e alinhada com os objetivos estratégicos da empresa tende-se a haver redução dos conflitos ou serem minimizados de tal sorte que não comprometam as relações das empresas com fornecedores, clientes e concorrentes.

Neste sentido, a Bovespa, ao lançar as categorias que designam o nível de governança corporativa como de novo mercado (NM) e os níveis diferenciados de governança corporativa (NDGC), teve a intenção de reduzir a assimetria de informação entre os acionistas e organizações para o fornecimento de informações mais transparentes, além de diminuir o custo de capital das empresas que adotam essas regras, conforme explica (AGUIAR et al., 2004).

As boas práticas de governança corporativa são responsáveis por gerar maior transparência, a conquista de novos investidores, aumentando, assim, o volume das transações, ao mesmo tempo em que ocorre uma melhora da expectativa dos preços das ações das adotantes dos níveis diferenciados de governança corporativa, proporcionando maior retorno sobre o patrimônio líquido e de longo prazo, bem como a redução dos custos de captação.

Contudo, a dificuldade em encontrar indicadores que evidenciem as boas práticas de governança corporativa (MOURA et al., 2016) se torna uma lacuna na literatura e nas pesquisas com essa temática. Essa ausência se configura em um problema de pesquisa: como criar um indicador de governança corporativa para avaliar as boas práticas de governança corporativa de empresas inseridas na BM\&FBovespa com base em variáveis não financeiras?.

\section{METODOLOGIA}

Logo, o objetivo geral deste trabalho é construir um indicador para a avaliação das boas práticas de governança corporativa (MOURA et al., 2016) adotadas por uma amostra de 193 empresas listadas na Bm\&FBovespa via Análise de Componentes Principais - ACP. Neste sentido, faz-se a discussão sobre construção do indicador de governança corporativa com base na verificação da adoção de boas práticas de governança corporativa (MOURA et al., 2016), a fim de evitar fraudes ou problemas éticos em relação às práticas de governança adotadas (AGUILERA et al., 2018). Logo, foram selecionadas empresas nacionais que estão listadas na Bm\&FBovespa, aplicando-se a ACP.

Este artigo está estruturado em quatro seções além dessa introdução: a seção que discute a teoria de governança corporativa, chamada de teoria de base; a segunda que explica os procedimentos 
metodológicos; uma terceira sessão chamada de análise de resultados; e uma quarta seção que trata das considerações finais.

\section{DISCUSSÃO TEÓRICA}

\section{Origem da Governança Corporativa}

A teoria relacionada à governança corporativa vem ganhando cada vez mais espaço no meio acadêmico e nas organizações, principalmente, a partir dos escândalos ocorridos como fraudes em demonstrações contábeis que acarretaram na falência de várias empresas multinacionais norte-americanas. Essas falências causaram prejuízos incalculáveis ao mercado financeiro, gerando a preocupação entre acionistas/cotistas em buscar mecanismos mais eficientes de conciliar os interesses dos gestores e investidores com base numa gestão eficiente e com mais transparência. Diante disso, surge em 1990, nos Estados Unidos, a criação de uma lei chamada Sarbanes-Oxley, que vigora desde julho de 2002, que rege o relacionamento entre os gestores e investidores (ANDRADE et al., 2006).

Pode-se afirmar, portanto, que a governança corporativa surgiu, justamente, para amenizar o que teoricamente ficou conhecido como 'conflito de agência', claramente em evidência após o emprego da ideia de desvinculação da gestão organizacional da propriedade, ou seja, sem a sobreposição das funções de proprietário e de gestor, onde o desenvolvimento de um conjunto eficiente de mecanismos baseados tanto em incentivos aos gestores como em monitoramento pelos investidores busca conciliar o comportamento de executivos com o interesse dos acionistas.

Isto comumente ocorre quando os proprietários (investidores, acionistas/cotistas) também identificados como principal atribuem a um agente especializado (executivo) o poder de tomada de decisão sobre as suas propriedades, no entanto, quando os interesses do agente não estão em conformidade com os interesses dos proprietários entra em cena o conflito de agência ou o que também é definido como conflito agente-principal. Mais à frente fica clara esta ideia de conflito de agência que será abordado neste trabalho com a discussão sobre a teoria da agência que é de fundamental importância para entendimento da teoria de governança corporativa. Neste sentido,

Um relacionamento de agência é um contrato realizado entre uma ou mais pessoas, onde o principal delega a um agente o poder de tomada de decisão nas tarefas desempenhadas em seu favor. Quando as partes não encontram um consenso entre si, passam a buscar a maximização das suas utilidades pessoais, ficando claro que o agente não agirá segundo o interesse do principal.

\section{Conceitos de governança corporativa}

Diversos conceitos e definições sobre governança corporativa são apresentados por autores e institutos que possuem domínio nesta teoria, haja vista que não há um modelo universal de boas práticas tomado como padrão de aplicação nas organizações, pois existem estruturas organizacionais diferenciadas que levam em consideração as tipologias de propriedade: quanto à organização (familiar, consorciada, estatal, anônima); quanto ao capital (fechada ou aberta); e quanto à distribuição das ações (concentrada ou 
pulverizada). Portanto, cada organização (empresa, companhia, instituição, etc.) adotará o modelo mais adequado à sua estrutura organizacional ou ao modelo de negócio.

Para Abreu et al. (2011): “A governança corporativa é um conjunto de práticas, processos, costumes, políticas, leis, regulamentos e relacionamentos entre os membros de uma empresa, que regem a maneira como ela é dirigida, administrada ou controlada". O Instituto Brasileiro de Governança Corporativa define governança corporativa como “(...) sistema pelo qual as empresas e demais organizações são dirigidas, monitoradas e incentivadas, envolvendo os relacionamentos entre sócios, conselho de administração, diretoria, órgãos de fiscalização e controle e demais partes interessadas".

Portanto, a governança corporativa envolve um conjunto de práticas para uma gestão organizacional eficiente e profissionalizada resguardando os interesses tanto do principal como do agente, preservando a perenidade da propriedade, além de regulamentos para garantir o bom relacionamento entre todos os membros que compõem a estrutura organizacional: propriedade, conselho de administração, conselho fiscal, nível C (diretoria), auditoria independente e demais partes interessadas (Stakeholders).

\section{Mecanismos de governança corporativa}

Visando ao alcance das metas e objetivos por parte das organizações é que surge a necessidade de implementação de eficientes mecanismos de governança corporativa caracterizados pelo monitoramento dos procedimentos, análise do desempenho financeiro, alinhamento de controle de gestão, além da avaliação de performance.

É com base nos fatores de estrutura de propriedade e prestação de contas que se pode entender a aplicação dos mecanismos de governança corporativa, onde as ações são realizadas de maneira descentralizada, ou seja, distribuída entre os membros que compõem a estrutura organizacional, bem como uma cultura tempestiva de divulgação dos demonstrativos financeiros.

De certa forma, pode-se entender que os mecanismos adotados pela gestão dentro de uma estrutura organizacional visam sempre defender e preservar os interesses dos acionistas e das demais partes interessadas (SHLEIFER et al., 1997). Os mecanismos de governança corporativa são eficientes quando previnem e amenizam os custos de agência decorrentes dos conflitos de interesse entre tomadores de decisão e os investidores (SILVEIRA et al., 2004).

Outros dois fatores de relevância a serem considerados na análise dos mecanismos de governança corporativa é a estrutura de capital e a composição do conselho de administração. A estrutura de capital prima pelo desempenho da empresa, pela captação de recursos financeiros e valorização no mercado de suas ações; por outro lado, a composição do conselho de administração preocupa-se com a criação de modelos de maximização dos valores em termos de lucros, característica comportamental de gerenciamento das grandes companhias (ABREU et al., 2011).

O nível de adaptação aos padrões de grandes empresas internacionais só é possível colocando-se em prática rigorosos e sofisticados mecanismos de governança corporativa, onde a maioria das empresas brasileiras ainda está aquém das empresas norte-americanas que já incorporaram com bastante maturidade 
esta cultura de gestão. Para tal, é importante que a companhia possua um comitê de governança corporativa com membros independentes de cargos na diretoria, além do comitê de remuneração e o comitê de auditoria. A companhia deve divulgar suas diretrizes de governança corporativa com o mínimo de requisitos especificados e, por fim, adotar e divulgar um código de condutas e de ética para todos os que formam a estrutura organizacional reconhecida e aplicada também aos conselheiros e à diretoria.

\section{O desenvolvimento da governança corporativa nas empresas brasileiras}

Observando o atual cenário de competição econômica, do qual as empresas brasileiras fazem parte deste contexto, onde as exigências dos investidores internacionais por uma gestão especializada é cada vez mais evidente e a escassez de recursos é grande, os mecanismos sofisticados de governança corporativa são ainda mais valorizados e adotados por empresas multinacionais estrangeiras. No entanto, pode-se dizer que a realidade de boa parcela das empresas brasileiras encontra-se em estágios intermediários de desenvolvimento para que se possa alcançar uma governança corporativa de alto nível.

De acordo com Wood Junior (1995), a cultura do 'jeito' brasileiro de administrar ainda é marcada por níveis diversificados de governança corporativa das empresas nacionais, visto que, embora algumas empresas adotem um gerenciamento de porte internacional, outras, representadas até mesmo por setores inteiros, insistem em uma prática patrimonialista, tecnocrática e conservadora. Nessas empresas com visão tradicionalista percebe-se muito forte a imagem do gestor e ao mesmo tempo proprietário, caracterizado por uma estrutura familiar de negócio, onde as práticas gerenciais são pouco profissionalizadas.

As fases da governança corporativa no mercado brasileiro ocupam atualmente um estágio de transição do modelo tradicional para um modelo emergente. Destacam-se três estágios nesse processo de mudança das empresas brasileiras: modelo atual, modelo emergente e modelo de mercado (STEINBERG, 2003).

No modelo atual, o gerenciamento da organização é realizado por um número restrito de acionistas majoritários sem a utilização de práticas profissionalizadas de governança corporativa. Já no modelo emergente, o gerenciamento da organização é feito por um número pequeno de acionistas majoritários, utilizando-se de uma gestão profissionalizada e abertura de capital para a execução de suas estratégias. No modelo de novo mercado, a gestão é compartilhada, com a designação de suas especificidades, fundamentadas em valores e ideais com aplicação de uma governança corporativa formal, tendo a capacidade e as condições de competição financeira global (ABREU et al., 2011).

\section{Instituições nacionais que trabalham na divulgação e capacitação para adoção das boas práticas de governança corporativa entre as empresas brasileiras}

As empresas brasileiras têm buscado com muito esforço a sua profissionalização e a modernização mediante a adoção de mecanismos de governança corporativa. Muitas dessas empresas estão aplicando as boas práticas de governança corporativa (MOURA et al., 2016) que favorecem o desenvolvimento no mercado de capitais. Esse caminho que as empresas brasileiras estão trilhando deve-se muito ao surgimento 
e fortalecimento do Instituto Brasileiro de Governança Corporativa (IBGC); também pela classificação das empresas nacionais na bolsa de valores (Bm\&FBovespa), com fundamento nos Níveis Diferenciados de Governança Corporativa (NDGC); a atuação da Comissão de Valores Mobiliários (CVM); atuação do BNDS e da Secretaria de Previdência Complementar do Governo Federal (ABREU et al., 2011).

Percebem-se que os esforços realizados por esses institutos têm como finalidade principal a valorização dos acionistas minoritários e amenizar os conflitos existentes entre tais acionistas minoritários e os majoritários. A atuação desses institutos ajuda na regulação de mercado de capitais favorecendo aos acionistas a utilização de práticas de governança corporativa (MOURA et al., 2016) como uma certificação de quem precisa de recurso financeiro para capital de giro ou para aumento de riqueza.

Em países desenvolvidos, as empresas chegam a valer muito além dos seus lucros anuais, pois as boas práticas adotadas de governança corporativa impulsionam as mesmas a maximizarem os seus lucros e a executarem abertura de capital, conhecido como pulverização de capital. No entanto, a postura pouco profissionalizada das empresas brasileiras vem mudando devido às restrições de recursos financeiros que forçam a abertura de capital, promovendo a consequente adaptação às exigências mundiais, tornando-as globalmente competitivas.

\section{As boas práticas de Governança Corporativa}

Como foi mencionado anteriormente não existe uma regra específica ou doutrinamento sobre o que é consensualmente definido como boas práticas de governança corporativa. Porém, o Instituto Brasileiro de Governança Corporativa adota como referência uma cartilha definida como código de referência que pode ser adotada por qualquer outra organização, levando-se em consideração as suas especificidades do arcabouço regulatório, seja ele compulsório ou facultativo, que, portanto, não se trata de um conjunto de práticas que devem ser obrigatoriamente adotadas exaustiva e mecanicamente. Neste sentido, o código de boas práticas de governança corporativa formulado pelo IBGC promove a adoção de uma postura de reflexão por meio de fundamentos e práticas em relação à atitude da organização, conforme a sua estrutura, realidade e ciclo de vida.

Deste modo, é importante destacar a importância dos princípios básicos de governança corporativa que podem e devem ser aplicados a qualquer tipo de organização, que são fundamentais para o desenvolvimento da boa governança. Logo, é fato concreto de que os princípios, diferentemente das práticas, são condições indispensáveis quando se quer alcançar uma boa governança corporativa (IBGC, 2017)

As práticas remetem à ideia das ações que deverão ser tomadas pela gestão da organização para se assegurar a confiabilidade, o bom relacionamento, as obrigações, direitos e deveres de cada uma das partes envolvidas no processo, uma vez que devem ser resguardados os interesses de cada uma das partes envolvidas, enquanto que os princípios são recomendações objetivas para o alinhamento dos interesses buscando preservar e otimizar valor econômico para a organização a longo prazo, facilitando a captação de recursos, promovendo uma gestão de qualidade, e a sustentabilidade do negócio (IBGC, 2017). 
Os princípios básicos de governança corporativa são caracterizados pela: transparência, que visa a reduzir a assimetria de informações por meio da divulgação das mesmas para resguardar o interesse de todos, não se caracterizando somente pelas informações normativas impostas por lei ou regulamentações e nem tão somente às de cunho de performance econômico-financeiro, mas que incorpore também, as de fatores intangíveis que sinalizam a ação gerencial e que asseguram a preservação e a otimização do valor da organização, (IBGC, 2017); equidade: todos devem receber o mesmo tratamento e igualitário, entre todas as partes envolvidas em torno desta organização (sócios, acionistas, gestor, stakeholders, etc.), assegurando os seus direitos, deveres, necessidades, interesses e expectativas, (IBGC, 2017).

Além desses, têm-se: prestação de contas: os gestores devem agir com responsabilidade e diligência de acordo com a posição que ocupam, assumindo de maneira integral com as consequências de seus atos não agindo de forma negligente ou omissa, onde deverão prestar contas de seus papéis claramente, concisamente, compreensivelmente e tempestivamente, (IBGC, 2017); e responsabilidade corporativa: os gestores devem primar pela viabilidade econômico-financeira das organizações, reduzir os efeitos de externalidades negativas do mercado sobre seus negócios e suas transações e considerar as positivas, considerando no negócio da organização os diversos recursos, que podem ser: financeiro, matéria-prima, pessoal, conhecimentos, social, ambiental, reputação, etc..

\section{Trabalhos correlatos}

Estudos relacionados à construção de indicadores tanto financeiros como não financeiros têm se preocupado em atestar se um conjunto de indicadores contribui positivamente para a geração de valor da empresa (CASELANI et al., 2006). As conclusões com base nesses estudos demonstraram que os indicadores não financeiros são de extrema importância, pois funcionaram como boas variáveis explicativas da criação de valor para as empresas (como lucro líquido, fluxo de caixa livre, EVA e EBIT).

Observou-se, também, que a inclusão de variáveis financeiras ajuda na avaliação da qualidade dos modelos (destacando-se endividamento e margem operacional). Foi concluído que a combinação dos indicadores explica a geração de valores para as empresas, a partir do momento em que a tomada de decisão dos gestores é influenciada pelas informações não financeiras. Foi constatado, também, que os especialistas que tomam decisões com base em informações não financeiras conseguem melhores estimativas dos resultados empresariais (FRANCISCO, 2014).

Os trabalhos de Ittner et al. (1998), produziram resultados semelhantes e caracterizados pela combinação bem-sucedida de indicadores financeiros com não financeiros para explicar a agregação de valor. A pesquisa realizada por Amir et al. (1996) confirmou que a combinação desses indicadores está relacionada com a criação de valor. É importante ressaltar que este trabalho se propõe a construir o indicador de governança corporativa para uma amostra de empresas brasileiras listadas na Bm\&FBovespa com base nos estudos de criação de indicadores não financeiros. 


\section{Indicadores não-financeiros em Governança Corporativa}

Os indicadores não-financeiros em governança corporativa caracterizam-se pela tentativa de explicar as práticas adotadas nos procedimentos gerenciais da organização, fundamentada na área de negócio à qual está estruturada, com vistas ao seu desempenho global. Os indicadores não-financeiros têm como objetivo principal avaliar a performance utilizando-se de variáveis relacionadas à criatividade, à inovação, à transparência, aos procedimentos éticos, à responsabilidade social, etc.. Logo, para que seja realizada a avaliação da performance da empresa, faz-se necessário a mensuração da utilização dos mecanismos (procedimentos) de governança corporativa.

Sabe-se que a capacidade de previsão da criação de valor pode ser encontrada nos mecanismos utilizados de governança corporativa e de incoerências em processos e procedimentos que se constituem como medidas não financeiras. Ressalta-se que o acesso a essas medidas ou variáveis torna-se difícil devido aos custos de obtenção e carência das políticas de compartilhamento das informações. Os estudos demonstram que ações proativas favorecem à prevenção, à antecipação e à influência nos resultados futuros das empresas. Portanto, tudo isso reforça a importância e utilização das variáveis não financeiras que são capazes de propiciar informações de desempenho futuro (PACE et al., 2003).

De acordo com Low et al. (1998), os indicadores não-financeiros retratam a percepção de visão estratégica da organização, capacidade de gestão de fluxo de caixa, confiança e credibilidade nos procedimentos gerenciais, atendimento às expectativas de inovação e abertura de capital para incorporar novos acionistas. A partir desse estudo, verificou-se que a mensuração dessas variáveis não financeiras influenciou diretamente na geração de valor para a empresa.

As seguintes variáveis não-financeiras foram trabalhadas: ampliação significativa de avaliação e recomendação das informações não financeiras pelos analistas em seus processos de tomada de decisões; maior interesse em fatores relacionados à execução estratégica, credibilidade na administração, com inovação e posicionamento mercadológico; alavancagem de captação de recursos de terceiros quando ocorre a facilidade de comunicação nas projeções de informações não financeiras mais corretas; a existência de relação entre as mudanças das informações e as variações no valor das ações e, por conseguinte, em seu custo de capital.

Várias empresas desenvolveram questionários para avaliação de desempenho com base em variáveis não financeiras caracterizadas por listas detalhadas de mecanismos de governança corporativa. Tais variáveis configuram pesquisas qualitativas por meio de questionários que confirmaram as melhores práticas adotadas de governança corporativa na composição de indicadores não financeiros para geração de maior valor no mercado, visto que esses trabalhos foram realizados por Black et al. (2003), Beiner et al. (2003), dentre outros.

\section{Análise de Componentes Principais (ACP)}

A Análise de Componentes Principais é uma técnica estatística multivariada que busca a partir de um conjunto de $\mathrm{k}$ variáveis originalmente correlacionadas a geração de outro conjunto de $p$ variáveis não 
correlacionadas, onde $k=p$, de modo que este novo conjunto de variáveis são chamadas de componentes principais, ou seja, resultados de combinações lineares das variáveis originais.

Essas componentes principais são construídas de forma a alcançar a máxima variabilidade dos dados redistribuída em eixos ortogonais com a menor perda possível de informação, onde os primeiros componentes concentram a maior parte de toda a variância explicada. Portanto, a lógica da ACP consiste na explicação da estrutura de variância e covariância de um vetor aleatório, composto de k variáveis aleatórias através da construção dos componentes principais (MINGOTI, 2013). Essa técnica pode ser utilizada para geração de índices e agrupamento de variáveis em componentes principais que explicam a maior variabilidade do conjunto total de dados, ou seja, agrupamento mais significativo através de eixos ortogonais (MANLY, 1986).

Se a distribuição de probabilidades do vetor aleatório de $k$ variáveis originais é normal, então o vetor de $p$ componentes principais independentes também têm distribuição de probabilidades normal e não correlacionadas. No entanto, ressalta-se que não é uma exigência fundamental para que a ACP seja utilizada tendo como obrigação atender a suposição de um vetor aleatório com distribuição normal das variáveis originais (MINGOTI, 2013).

Outra característica importante da ACP é que se alguma padronização for realizada na matriz de dados originais, então a obtenção das combinações lineares, que maximizam a variabilidade total, deverá ter como ponto de partida a matriz de covariâncias do conjunto de dados das variáveis padronizadas. $O$ tipo de padronização mais comumente utilizado na literatura é a normalização do conjunto de dados iniciais, aplicando-se a diferença entre cada valor da variável original e a média de seus valores e, em seguida, dividindo-se esta diferença pelo desvio-padrão.

Ao determinar os valores numéricos que são resultados das combinações lineares, torna-se possível a obtenção dos escores de cada elemento amostral de forma que há a possibilidade de análise dos componentes principais por meio de outras técnicas estatísticas como análise de variância, regressão, etc.. A ACP consiste em encontrar as combinações lineares das variáveis originais conforme $\boldsymbol{Z}_{\boldsymbol{i}}=a^{T} \boldsymbol{X}=$ $\sum_{i=1}^{p} a_{i} \boldsymbol{X}_{\boldsymbol{i}}$, onde $\boldsymbol{Z}$ é um vetor de componentes principais representada por: $\boldsymbol{Z}=\left[\begin{array}{c}Z_{1} \\ \vdots \\ z_{n}\end{array}\right]$, resultante de uma matriz de dados iniciais $\boldsymbol{X}$ denotada por: $\boldsymbol{X}=\left[\begin{array}{ccc}x_{11} & \cdots & x_{1 p} \\ \vdots & \ddots & \vdots \\ x_{n 1} & \cdots & x_{n p}\end{array}\right]$, tendo como ponto de partida a matriz de correlação das variáveis originais, designada por: $\Sigma=$ $\left[\begin{array}{cccccc}1 & r\left(x_{1} x_{2}\right) & r\left(x_{1} x_{3}\right) & r\left(x_{1} x_{4}\right) & \ldots & r\left(x_{1} x_{p}\right) \\ r\left(x_{2} x_{1}\right) & 1 & r\left(x_{2} x_{3}\right) & r\left(x_{2} x_{4}\right) & \ldots & r\left(x_{2} x_{p}\right) \\ r\left(x_{3} x_{1}\right) & r\left(x_{3} x_{2}\right) & 1 & r\left(x_{3} x_{4}\right) & \ldots & r\left(x_{3} x_{p}\right) \\ r\left(x_{4} x_{1}\right) & r\left(x_{4} x_{2}\right) & r\left(x_{4} x_{3}\right) & 1 & \ldots & r\left(x_{4} x_{p}\right) \\ \vdots & \vdots & \vdots & \vdots & \ddots & \vdots \\ r\left(x_{n} x_{1}\right) & r\left(x_{n} x_{2}\right) & r\left(x_{n} x_{3}\right) & r\left(x_{n} x_{4}\right) & \ldots & 1\end{array}\right]_{n x p}$ 
A ideia de utilização da ACP tem primeiramente como objetivo encontrar a matriz de correlação das variáveis originais para a solução da seguinte equação determinística para $\lambda,|\boldsymbol{\Sigma}-\lambda \boldsymbol{I}|=0$, em que $\lambda$ é vetor de autovalores e $\boldsymbol{\Sigma}$ é a matriz de correlações das variáveis originais de ordem nxp, padronizadas quando for o caso. Mas encontrar a solução da equação determinística significa atender a condição $a^{t} a=1$ para a resolução da equação matricial $(\boldsymbol{\Sigma}-\lambda \boldsymbol{I}) \boldsymbol{a}=0$, sendo que $\boldsymbol{a}$ é o conjunto de autovetores associados aos autovalores.

Conforme Santana et al. (2014), ao considerar a condição de que $a^{t} a=1$ encontram-se as componentes principais (CP's) pela maximização da variância de $\boldsymbol{Z}_{\boldsymbol{i}}$ e, portanto, $\operatorname{Var}\left(\boldsymbol{Z}_{\boldsymbol{i}}\right)=\boldsymbol{a}^{T} \boldsymbol{\Sigma} \boldsymbol{a}$, que geram as equações $\left\{\begin{array}{c}C P_{1}=a_{11} X_{1}+a_{12} X_{2}+\cdots+a_{1 n} X_{n} \\ C P_{2}=a_{21} X_{1}+a_{22} X_{2}+\cdots+a_{2 n} X_{n} \\ \cdot \\ \cdot \\ \cdot \\ C P_{n}=a_{n 1} X_{1}+a_{n 2} X_{2}+\cdots+a_{n n} X_{n}\end{array}\right.$.

\section{Procedimentos para a construção do indicador}

O procedimento metodológico sobre o ponto de vista da abordagem do problema é quantitativo, visto que esse tipo de pesquisa leva em consideração uma relação dinâmica entre o mundo real e o sujeito traduzido em números. Inicialmente, realizou-se um levantamento de obras que tratam a respeito do tema da governança corporativa indicando a sua origem, conceitos, princípios, sua utilização em empresas brasileiras, assim como, as instituições nacionais que trabalham na divulgação e capacitação para adoção das boas práticas de governança corporativa (MOURA et al., 2016) entre as empresas nacionais, além da classificação das mesmas em níveis de governança corporativa.

Também se buscou fundamentos nas obras de autores que já trabalharam na construção de indicadores fornecendo um entendimento das variáveis que podem ser utilizadas para averiguação de boas práticas de governança corporativa (MOURA et al., 2016). Incluiu-se ainda um referencial teórico para a fundamentação sobre a técnica estatística de ACP.

Posteriormente, com base em uma amostragem não-probabilística, foi utilizado um banco de dados com as informações de 193 empresas nacionais listadas na Bmf\&Bovespa do qual foram extraídas as variáveis que identificam a adoção de boas práticas de governança corporativa (MOURA et al., 2016) sobre "capital social" e "cronograma de eventos corporativos". A escolha dessas duas variáveis se deu pela disponibilidade no banco de dados online de tais informações. Essas variáveis foram categorizadas em escores (pontuação) de 0 (zero) a 3 (três), onde 0 (zero) representa baixo escore para determinada prática de governança corporativa e 3 (três) alto escore. Tal categorização permite a utilização dos escores de cada uma das variáveis para a construção do indicador de governança corporativa, sendo muito próximo à construção de uma escala tipo Likert, porém de quatro pontos.

Na sequência, visando o fácil entendimento da temática, utilizou-se um conjunto de variáveis identificadoras da adoção de boas práticas de governança corporativa para embasamento da discussão sobre a aplicação da técnica de ACP na construção do indicador de governança corporativa das empresas nacionais 
listadas na Bmf\&Bovespa. Por fim, de posse do indicador de governança corporativa, finaliza-se a temática da construção de indicadores de governança corporativa via ACP, fazendo-se um ranking dessas empresas nacionais por meio de uma análise intra e intersetoriais da economia nacional.

\section{Construção do indicador de governança corporativa via ACP}

Este trabalho utilizou as informações de "capital social" e "cronograma de eventos corporativos" de uma amostra de 193 empresas listadas na Bm\&fBovespa, com dados disponibilizados online e atualizados até 14 de junho de 2017. As informações foram extraídas de acordo com a categorização das variáveis dispostas no quadro 1.

Quadro 1: Resumo para a descrição das variáveis utilizadas para a mensuração das práticas de governança corporativa de 193 empresas brasileiras listadas na Bm\&Fbovespa.

\begin{tabular}{|c|c|c|c|}
\hline 2 & Variáveis & Práticas de governança corporativa & Escore \\
\hline \multirow{3}{*}{ Capital Social } & Seg_merc & $\begin{array}{l}\text { Segmento de mercado para os níveis } \\
\text { diferenciados de governança corporativa } \\
\text { (NDGC) definidos pela Bm\&Fbovespa. }\end{array}$ & $\begin{array}{l}\text { 0: nível diferente de } 1,2 \text { ou 3; } \\
\text { 1: nível } 1 ; \\
\text { 2: nível 2; } \\
\text { 3: nível 3. }\end{array}$ \\
\hline & Cap_Empresa & $\begin{array}{l}\text { Valor de capital da empresa em espécie } \\
\text { monetária (reais). }\end{array}$ & $\begin{array}{c}\text { 0: até } \mathrm{R} \$ 2.202 .265 .981,63 ; \\
\text { 1: de } \$ 2.202 .265 .981,64 \text { até } \\
\mathrm{R} \$ 26.568 .604 .720,76 ; \\
\text { 2: de } \mathrm{R} \$ 26.568 .604 .720,77 \text { até } \\
\mathrm{R} \$ 67.800 .000 .000,00 ; \\
\text { 3: acima de } \mathrm{R} \$ 67.800 .000 .000,00 .\end{array}$ \\
\hline & Perc_Ac_Ord & $\begin{array}{l}\text { Percentual de ações ordinárias em relação } \\
\text { ao total de ações }\end{array}$ & $\begin{array}{l}\text { 0: menos de } 25 \% \text { de ações ordinárias; } \\
\text { 1: de } 25,1 \% \text { até } 50 \% \text { de ações ordinárias; } \\
\text { 2: de } 50,1 \% \text { até } 75 \% \text { de ações ordinárias; } \\
\text { 3: acima de } 75 \% \text { de ações ordinárias. }\end{array}$ \\
\hline \multirow{7}{*}{$\begin{array}{l}\text { Cronograma de eventos } \\
\text { corporativos }\end{array}$} & Cump_Prz_Ent_CE & $\begin{array}{l}\text { Cumprimento de prazo para entrega de } \\
\text { calendário de eventos corporativos. }\end{array}$ & $\begin{array}{c}\text { 0: mais de um dia de atraso na entrega; } \\
\text { 1: um dia de atraso na entrega; } \\
\text { 2: entrega no prazo; } \\
\text { 3: entrega antecipada. }\end{array}$ \\
\hline & $\underset{\text { Cump_Prz_Leg_So }}{\text { C }}$ & $\begin{array}{c}\text { Cumprimento de prazo para entrega das } \\
\text { demonstrações financeiras do exercício } \\
\text { para legislação societária. }\end{array}$ & $\begin{array}{c}\text { 0: mais de um dia de atraso na entrega; } \\
\text { 1: um dia de atraso na entrega; } \\
\text { 2: entrega no prazo; } \\
\text { 3: entrega antecipada. }\end{array}$ \\
\hline & Cump_Prz_DFP & $\begin{array}{l}\text { Cumprimento de prazo para entrega das } \\
\text { demonstrações financeiras do exercício } \\
\text { padronizadas. }\end{array}$ & $\begin{array}{c}\text { 0: mais de um dia de atraso na entrega; } \\
\text { 1: um dia de atraso na entrega; } \\
\text { 2: entrega no prazo; } \\
\text { 3: entrega antecipada. }\end{array}$ \\
\hline & Cump_Realiz_AGO & $\begin{array}{l}\text { Cumprimento de prazo para a realização } \\
\text { da Assembleia Geral Ordinária (AGO). }\end{array}$ & $\begin{array}{c}\text { 0: mais de um dia de atraso na entrega; } \\
\text { 1: um dia de atraso na entrega; } \\
\text { 2: entrega no prazo; } \\
\text { 3: entrega antecipada. }\end{array}$ \\
\hline & $\begin{array}{c}\text { Cump_Ent_Form_ } \\
\text { Ref }\end{array}$ & $\begin{array}{l}\text { Cumprimento de prazo para entrega do } \\
\text { formulário de referência. }\end{array}$ & $\begin{array}{c}\text { 0: mais de um dia de atraso na entrega; } \\
\text { 1: um dia de atraso na entrega; } \\
\text { 2: entrega no prazo; } \\
\text { 3: entrega antecipada. }\end{array}$ \\
\hline & $\underset{\text { st }}{\text { Reun_Pub_C_Anali }}$ & $\begin{array}{l}\text { Cumprimento de prazo para reunião } \\
\text { pública com analistas. }\end{array}$ & $\begin{array}{c}\text { 0: mais de um dia de atraso na entrega; } \\
\text { 1: um dia de atraso na entrega; } \\
\text { 2: entrega no prazo; } \\
\text { 3: entrega antecipada. }\end{array}$ \\
\hline & Inf_1_Trim & $\begin{array}{c}\text { Cumprimento de prazo para entrega de } \\
\text { informações referentes ao primeiro } \\
\text { trimestre. }\end{array}$ & $\begin{array}{c}\text { 0: mais de um dia de atraso na entrega; } \\
\text { 1: um dia de atraso na entrega; } \\
\text { 2: entrega no prazo; } \\
\text { 3: entrega antecipada. }\end{array}$ \\
\hline
\end{tabular}

A tabela 1 mostra a descrição de como as variáveis de mensuração das práticas de governança corporativa foram categorizadas em valores de 0 a 3 . No caso das variáveis relacionadas ao cronograma de eventos corporativos as categorias foram: 0 para as empresas que tiveram mais de um dia de atraso na realização das tarefas de transparência e prestação de contas; 1 para as que executaram com um dia de 
atraso; 2 para as que executaram a tarefa em dia; e 3 para as que cumpriram as tarefas com pelo menos um dia de antecedência.

Para as variáveis de capital social a construção foi da seguinte forma: Capital da Empresa (Cap_Empresa): utilizou-se a técnica estatística análise de cluster pelo critério não hierárquico para fazer o agrupamento das empresas pela distância entre os valores monetários considerando o processo k-means (k médias para $\mathrm{k}$ agrupamentos pré-determinados), no caso tomou-se $k=4$, onde (0) designa empresas com capital social até $R \$ 2.202 .625 .981,63$; (1) designa empresas com capital social de $R \$ 2.202 .625 .981,64$ até $\mathrm{R} \$ 26.568 .604 .720,76 ;$ (2) designa empresas com capital social de $\mathrm{R} \$ 26.568 .604 .720,77$ até $\mathrm{R} \$ 67.800 .000 .000,00$; e (3) a partir de $\mathrm{R} \$ 67.800 .000 .000,01$.

Segmento de mercado (Seg_merc): valores categorizados conforme os preestabelecidos pela Bm\&FBovespa, sendo (0) para qualquer certificação diferente de Bovespa nível 1, Bovespa nível 2 e Novo Mercado; (1) para Bovespa nível 1; (2) para Bovespa nível 2; e (3) para Novo Mercado; e Percentual de Ações Ordinárias (Per_Ac_Ord): a ideia da distribuição e participação de investidores que detêm ações ordinárias foi categorizada como (0) para a designação de empresas com menos de 25\%; (1) de 25\% a menos de $50 \%$; (2) de $50 \%$ a menos de $75 \%$; e (3) a partir de $75 \%$ de ações ordinárias.

A partir da descrição das variáveis selecionadas para a mensuração das práticas de governança corporativa (MOURA et al., 2016) retiradas de uma amostra de 193 empresas listadas na Bm\&FBovespa, procedeu-se à aplicação da Análise de Componentes Principais. O pacote estatístico utilizado para o processamento e a análise dos dados foi o software SPSS for Windows versão 20.0.

A amostra de 193 empresas supera as exigências para aplicação da ACP em trabalhos científicos onde o mínimo necessário é de 50 (cinquenta observações). A razão entre o número de casos e a quantidade de variáveis deve ser de pelo menos 5 (cinco), o que no caso deste trabalho a razão é de 193/10 (igual a 19,3) observações por variáveis. Portanto, o pressuposto inicial foi atendido.

Na sequência, foi gerado a tabela 2, a partir da amostra de 193 empresas, para testar a validade do conjunto de dados à aplicação da ACP com fundamento no teste de Kaiser Meyer Olkin (KMO) que mede a adequação da amostra. O valor da estatística KMO que atesta a adequação da amostra deve ser de no mínimo igual a 0,5 , onde esses valores variam de 0 a 1.

Tabela 2: Teste KMO e o Teste de Esferecidade de Bartlett.

\begin{tabular}{|c|c|c|}
\hline \multicolumn{2}{|c|}{ Estatística de Kaiser-Meyer-Olkin de Adequação da amostra (KMO). } & 0,689 \\
\hline \multirow{3}{*}{ Teste de Esferecidade de Bartlett } & Valor de aproximação da estatística Qui-quadrado & 379,927 \\
\cline { 2 - 3 } & Graus de liberdade & 45 \\
\cline { 2 - 3 } & Sig. (P_valor) & 0,000 \\
\hline
\end{tabular}

A tabela com os dados gerados pelo SPSS versão 20.0 permitem concluir que há adequação da amostra para aplicação da ACP, uma vez que o valor mínimo aceitável da estatística KMO é de 0,5 e o resultado gerado é de 0,689>0,5, além do mais, o valor de 0,689 é muito próximo de 0,7 , mínimo defendido por (HAIR, 2009). Percebe-se também, a partir do quadro 2, que o teste de esferecidade de Bartlett é significativo ao nível de 1\%, ou seja, a hipótese de que não há correlação entre o conjunto de variáveis (matriz 
identidade das correlações das variáveis originais) é rejeitada, o que mais uma vez justifica a adequação dos dados à aplicação da ACP.

Desta forma, prosseguiu-se com a discussão da temática de geração do indicador de governança corporativa, proposto por este trabalho, com base no procedimento que calcula a média ponderada das componentes principais que possuem autovalores maiores ou iguais à unidade, ou seja, os componentes responsáveis por variâncias maiores ou iguais a 1 (autovalores maiores ou iguais a 1) (FRANCISCO, 2014).

A justificativa para se utilizar o procedimento de ponderação das componentes principais somente pelos autovalores maiores ou iguais a um é pelo fato de que a construção de indicador com base somente na primeira componente principal é responsável por uma pequena explicação da variabilidade total dos dados; e quando já se utiliza para a construção de indicador todos os componentes principais as últimas componentes conseguem explicar uma variabilidade pouco significativa (quase sempre menor do que 1) (KRISHNAKUMAR et al., 2008).

O cálculo do Índice de governança corporativa deu-se primeiramente com a obtenção das componentes principais compostas pelas combinações lineares das variáveis originais de práticas de governança corporativa e em seguida foi realizada a média ponderada desses componentes com base nos seus respectivos autovalores. E finalmente, para a padronização de escala do índice de governança corporativa das empresas brasileiras, aplicou-se uma transformação uniforme para o intervalo [0,1], onde os valores mais próximos de 0 (zero) indicam baixa governança corporativa e valores mais próximos de 1 (um) indicam alta governança corporativa.

Os resultados apresentados na tabela 3, demonstram como foram extraídas as quatro PCs (combinações lineares) utilizadas para a construção do indicador de governança corporativa via análise de componentes principais pelo critério do IGC_PAD_KAISER, levando em consideração os percentuais de variância explicada.

Tabela 3: Variância total explicada pela Análise de Componentes Principais (ACP).

\begin{tabular}{|c|c|c|c|c|c|c|}
\hline \multirow{2}{*}{$\begin{array}{c}\text { Componentes } \\
\text { Principais }\end{array}$} & \multicolumn{3}{|c|}{ Autovalores } & \multicolumn{2}{c|}{ Extração das somas com maiores carregamentos } \\
\cline { 2 - 7 } & Total & \% de variância & $\begin{array}{c}\text { \% de variância } \\
\text { acumulada }\end{array}$ & Variância & \% de variância & $\begin{array}{c}\text { \% de variância } \\
\text { acumulada }\end{array}$ \\
\hline $\mathbf{1}$ & $\mathbf{2 , 7 6 8}$ & $\mathbf{2 7 , 6 8 5}$ & $\mathbf{2 7 , 6 8 5}$ & $\mathbf{2 , 7 6 8}$ & $\mathbf{2 7 , 6 8 5}$ & $\mathbf{2 7 , 6 8 5}$ \\
\hline $\mathbf{2}$ & $\mathbf{1 , 6 5 1}$ & $\mathbf{1 6 , 5 1 2}$ & $\mathbf{4 4 , 1 9 7}$ & $\mathbf{1 , 6 5 1}$ & $\mathbf{1 6 , 5 1 2}$ & $\mathbf{4 4 , 1 9 7}$ \\
\hline $\mathbf{3}$ & $\mathbf{1 , 1 3 0}$ & $\mathbf{1 1 , 2 9 8}$ & $\mathbf{5 5 , 4 9 5}$ & $\mathbf{1 , 1 3 0}$ & $\mathbf{1 1 , 2 9 8}$ & $\mathbf{5 5 , 4 9 5}$ \\
\hline $\mathbf{4}$ & $\mathbf{1 , 0 1 1}$ & $\mathbf{1 0 , 1 0 6}$ & $\mathbf{6 5 , 6 0 1}$ & $\mathbf{1 , 0 1 1}$ & $\mathbf{1 0 , 1 0 6}$ & $\mathbf{6 5 , 6 0 1}$ \\
\hline 5 & 0,911 & 9,107 & 74,709 & & & \\
\hline 6 & 0,725 & 7,255 & 81,963 & & & \\
\hline 7 & 0,587 & 5,867 & 87,830 & & & \\
\hline 8 & 0,474 & 4,738 & 92,568 & & & \\
\hline 9
\end{tabular}

A partir da tabela 3 é possível perceber que os dados referentes às práticas de governança corporativa de uma amostra de 193 empresas podem ser explicados pelos 4 (quatro) primeiros componentes principais identificados em negrito. Tais componentes são responsáveis por cerca de $65,601 \%$ da variabilidade total explicada pelos dados, constituindo, portanto, as combinações lineares mais expressivas para a construção do indicador de governança corporativa com base nas variáveis de 'capital social' e 
'cronograma de eventos'. Além do percentual considerável de variabilidade os resultados chamam atenção para os componentes com autovalores maiores ou iguais a 1.

Tabela 4: Matriz de componentes principais do conjunto de dados.

\begin{tabular}{|c|c|c|c|c|c|}
\hline Variáveis & CP 1 & CP 2 & CP 3 & CP 4 & $-0,082$ \\
\hline Inf_1_Trim & 0,798 & 0,062 & 0,079 & 0,652826 \\
\hline Cump_Ent_Form_Ref & 0,738 & $-0,004$ & $-0,095$ & 0,057 \\
\hline Cump_Prz_DFP & 0,731 & 0,039 & $-0,181$ & 0,049 \\
\hline Cump_Realiz_AGO & 0,709 & 0,128 & 0,072 & $-0,004$ & 0,556770 \\
\hline Cump_Prz_Leg_Soc & 0,688 & $-0,009$ & $-0,170$ & 0,079 \\
\hline Reun_Pub_C_Analist & 0,181 & $-0,375$ & 0,655 & 0,570726 \\
\hline Cap_Empresa & 0,118 & $-0,552$ & 0,572 & $-0,101$ & 0,524025 \\
\hline Seg_merc & 0,089 & 0,729 & 0,459 & 0,034 & 0,658893 \\
\hline Cump_Prz_Ent_CEC & $-0,077$ & $-0,156$ & $-0,138$ & 0,656617 \\
\hline Perc_Ac_Ord & $-0,129$ & 0,792 & 0,248 & 0,751366 \\
\hline
\end{tabular}

Pela tabela 4 é possível identificar que primeira componente principal (coluna 1) tem melhor capacidade de predição, pois apresenta os itens com as maiores cargas fatoriais que indicam alta explicação do componente por tais variáveis e as mesmas estão agrupadas no componente principal de maior variabilidade explicada, cujos valores estão destacados em cinza, relacionadas ao cronograma de eventos corporativos (Inf_1_Trim, Cump_Ent_Form_Ref, Cump_Prz_DFP, Cump_Realiz_AGO e Cump_Prz_Leg_Soc) aumentam.

Isso demonstra que essas variáveis podem ser agregadas para explicar o indicador de governança corporativa com fundamento nos princípios de transparência e prestação de contas, pois essas variáveis estão relacionadas a divulgação de calendário das informações referentes às demonstrações financeiras, além da reunião da Assembleia Geral onde as decisões importantes podem ser discutidas e decididas com a maioria das partes envolvidas.

A segunda componente principal (coluna 2) explica também parte considerável da variabilidade dos dados agregando fortemente as variáveis referentes ao capital social das empresas como (Perc_Ac_Ord e Seg_merc) grifadas pela cor cinza, onde tais variáveis concentram, respectivamente, aspectos importantes de governança corporativa como grande percentual de ações ordinárias que dão direito a voto nas decisões para este tipo de acionista, além da garantia de venda de suas ações por pelo menos $80 \%$ do valor no caso de venda do controle da empresa.

Também, informações sobre níveis diferenciados de governança corporativa definidos segundo critérios de certificação estabelecidos pela Bm\&fBovespa estão fortemente evidenciados nesta segunda componente principal. Precisas tem que explicar a relação das variáveis com o fator considerando as cargas e seus pesos que não aparecem no texto.

A coluna de comunalidades indica a proporção de variância comum ou compartilhada das variáveis distribuída entre os quatro componentes, ou seja, representa o poder de explicação da variável indicando o grau de importância da variável no IGC, onde nota-se que a variável relativa ao cumprimento do prazo de entrega do cronograma de eventos corporativos (Cump_Prz_Ent_CEC) é a mais significativa por compartilhar cerca de $93,3 \%$ de sua variabilidade. 
O modelo multivariado deduzido pela $\mathrm{ACP}$ para o $I G C_{[0,1]}$

Para a criação do indicador de governança corporativa segundo o procedimento de ponderação das CPs pelos autovalores maiores ou iguais a 1 , considerou-se que $\lambda_{i}=\operatorname{var}\left(C P_{i}\right)$, de modo que o coeficiente de ponderação é dado por $\lambda_{i}=\lambda_{i} / \sum_{i=1}^{4} \lambda_{i}$, o que fornece: $I G C=\frac{\lambda_{1} C \boldsymbol{P}_{1}+\lambda_{2} C \boldsymbol{P}_{2}+\lambda_{3} \boldsymbol{C} \boldsymbol{P}_{3}+\lambda_{4} \boldsymbol{C P} \boldsymbol{P}_{4}}{\sum_{i=1}^{4} \lambda_{i}}$. E visando à facilidade na interpretação dos resultados quantitativos, procedeu-se à padronização dos valores dentro de uma escala que varia de 0 a 1, uniformizando-se a distribuição pelo modelo: $\operatorname{IGC}_{[0,1]}=[\operatorname{IGC}-\operatorname{Mín}(\operatorname{IGC})] /$ [Máx $(I G C)-M i ́ n(I G C)]$.

Sendo esta última função, $\mathrm{IGC}_{[0,1]}$, o modelo gerador dos indicadores individuais das 193 empresas listadas na Bm\&FBovespa quanto às práticas de governança corporativa desenvolvidas de acordo com as suas estruturas organizacionais de negócios. Com base na extração das quatro componentes principais que concentram a maior parte da variabilidade total dos dados e fazendo a ponderação pelos autovalores maiores ou iguais a um, tem-se, com base na matriz de dados, o seguinte modelo multivariado para o $I G C_{[0,1]}: I G C_{[0,1]}=\frac{2,768496 * \mathrm{CP}_{1}+1,651223 * \mathrm{CP}_{2}+1,129783 * \mathrm{CP}_{3}+1,010639 * \mathrm{CP}_{4}}{2,768496+1,651223+1,129783+1,010639}$.

\section{Análise dos resultados e o ranking das 20 melhores empresas segundo o $\mathrm{IGC}_{[0,1]}$}

Os resultados após a construção do indicador de governança corporativa via ACP, com o procedimento que considera os autovalores maiores ou iguais a um para ponderação das componentes principais, permitiram fazer um ranking das 20 melhores empresas listadas na Bm\&fBovespa segundo as suas práticas adotadas de governança corporativa caracterizadas pelas variáveis de capital social e cronograma de eventos corporativos. A classificação dessas empresas é mostrada a seguir na tabela 6.

Tabela 6: Ranking das 20 empresas com os melhores indicadores de governança corporativa com base nas suas práticas adotadas relacionadas ao capital social e cronograma de eventos corporativos.

\begin{tabular}{|c|c|c|c|}
\hline Empresas listadas na Bm\&FBovespa & NDGC da Bm\&FBovespa & IGC [01] & Capital Social \\
\hline ENGIE BRASIL ENERGIA S.A. & NOVO MERCADO & 1,00 & $\mathrm{R} \$ 2.829 .055 .259,66$ \\
\hline BR PROPERTIES S.A. & NOVO MERCADO & 0,93 & $\mathrm{R} \$ \mathbf{2 . 3 6 1 . 5 2 1 . 6 9 6 , 0 4}$ \\
\hline COSAN S.A. INDÚSTRIA E COMERCIO & NOVO MERCADO & 0,93 & $\mathrm{R} \$ 3.999 .074 .943,92$ \\
\hline EMBRAER S.A. & NOVO MERCADO & 0,93 & $\mathrm{R} \$$ 4.789.617.052,42 \\
\hline RUMO S.A. & NOVO MERCADO & 0,93 & $\mathrm{R} \$ \mathrm{7} 7.014 .897 .097,82$ \\
\hline TIM PARTICIPACOES S.A. & NOVO MERCADO & 0,93 & $\mathrm{R} \$ 9.913 .414 .421,74$ \\
\hline MRV ENGENHARIA E PARTICIPACOES S.A. & NOVO MERCADO & 0,93 & $\mathrm{R} \$ 4.769 .944 .997,63$ \\
\hline CCX CARVÃO DA COLÔMBIA S.A. & NOVO MERCADO & 0,91 & $\mathrm{R} \$ 742.186 .771,18$ \\
\hline COSAN LOGISTICA S.A. & NOVO MERCADO & 0,91 & $\mathrm{R} \$ 1.534 .892 .538,49$ \\
\hline GRENDENE S.A. & NOVO MERCADO & 0,91 & $\mathrm{R} \$ 1.231 .301 .604,46$ \\
\hline M.DIAS BRANCO S.A. IND COM DE ALIMENTOS & NOVO MERCADO & 0,91 & $\mathrm{R} \$ 1.765 .278 .466,94$ \\
\hline SONAE SIERRA BRASIL S.A. & NOVO MERCADO & 0,91 & $\mathrm{R} \$ 1.397 .865 .823,00$ \\
\hline EDP - ENERGIAS DO BRASIL S.A. & NOVO MERCADO & 0,89 & $\mathrm{R} \$ 4$ 4.682.715.947,12 \\
\hline PORTO SEGURO S.A. & NOVO MERCADO & 0,89 & $\mathrm{R} \$ 3.500 .000 .000,00$ \\
\hline CENTRAIS ELET BRAS S.A. - ELETROBRAS & BOVESPA NIVEL 1 & 0,87 & $\mathrm{R} \$ 31.305 .331 .463,74$ \\
\hline FERTILIZANTES HERINGER S.A. & NOVO MERCADO & 0,85 & $\mathrm{R} \$ 594.164 .902,56$ \\
\hline BIOSEV S.A. & NOVO MERCADO & 0,84 & $\mathrm{R} \$ 2.618 .213 .511,57$ \\
\hline SER EDUCACIONAL S.A. & NOVO MERCADO & 0,84 & $R \$ 377.048 .558,24$ \\
\hline ITAU UNIBANCO HOLDING S.A. & BOVESPA NIVEL 1 & 0,84 & $\mathrm{R} \$ 97.148 .000 .000,00$ \\
\hline VALE S.A. & BOVESPA NIVEL 1 & 0,84 & $\mathrm{R} \$ 77.300 .000 .000,00$ \\
\hline
\end{tabular}

De acordo com a tabela 6, percebe-se que o indicador de governança corporativa proposto com base nas variáveis de capital social e cronograma de eventos corporativos, ao classificar as 20 melhores empresas 
brasileiras listadas na Bm\&fBovespa, traz 17 que estão certificadas em Níveis Diferenciados de Governança Corporativa como Novo Mercado, revelando uma boa previsibilidade de empresas com alto padrão na adoção de práticas de governança corporativa.

Percebe-se também que existem empresas com capital social superior às demais empresas que estão agrupadas no mesmo nível de governança corporativa, como por exemplo, seis empresas IGC[0,1] em torno de 0,93 traz em destaque a TIM PARTICIPACÕES S.A. com capital de $R \$ 9.913 .414 .421,74$. No mesmo contexto, entre as cinco empresas com IGC[0,1] em torno de 0,91, destaca-se a M.DIAS BRANCO S.A. IND COM DE ALIMENTOS, com capital social de R\$1.765.278.466,94. De outras quatro empresas agrupadas com IGC $[0,1]$ em torno de 0,84 tem-se o destaque do ITAU UNIBANCO HOLDING S.A., com capital social de $\mathrm{R} \$ 97.148 .000 .000,00$. Essas disparidades entre capital social das empresas sugerem melhores estudos a posteriori onde as diferenças na adoção de práticas de governança corporativa (MOURA et al., 2016) ganham mais sentido quando são analisadas dentro dos setores de atividade que as agregam ou entre empresas de mesmo porte de desempenho global.

\section{CONSIDERAÇÕES FINAIS}

A partir da discussão teórica sobre governança corporativa percebe-se a importância da construção de indicadores para a avaliação de empresas que adotam mecanismos eficientes de gestão. Porém, a avaliação com base em indicadores de governança corporativa requer uma discussão teórica sobre a construção dos indicadores financeiros e não-financeiros que são combinados a fim de produzir o indicador de criação de valor para a empresa.

Obviamente, não houve a pretensão de construir, em pouco tempo, um indicador de governança corporativa que atendesse a todos os critérios de representatividade que detivesse pelo menos a maioria das variáveis para mensuração dos aspectos adotados como boas práticas de governança corporativa, pois foi trabalhado somente com as informações disponibilizadas online sobre capital social e cronograma de eventos corporativos. Contudo, concluiu-se que o indicador de governança corporativa proposto neste trabalho com variação de escala no intervalo 0 e 1 classificou coerentemente as 20 melhores empresas dentro de um ranking e a grande maioria delas, de fato, figuram entre as que apresentam certificação de novo mercado de acordo com os Níveis Diferenciados de Governança Corporativa (NDGC) da Bm\&FBovespa.

Propõe-se, para futuros trabalhos relacionados às práticas adotadas de governança corporativa com fundamentação teórica em indicadores não financeiros, a incorporação de mais variáveis para a criação de indicadores de governança corporativa, além das que foram apresentadas neste trabalho como capital social e cronograma de eventos corporativos. Recomenda-se que os estudos sobre a criação de indicadores de governança corporativa sejam comparados com os resultados construídos por instituições brasileiras renomadas na utilização desses indicadores como IBGC, CVM e Bm\&FBovespa, tudo isso com o propósito de atestar a coerência da construção dos indicadores e a robustez das estimativas. 


\section{REFERÊNCIAS}

ABREU, A. D.; COELHO, C. S.; RIBEIRO, D. A. D. S.; FERRREIRA, K.. A governança corporativa para o aprimoramento da gestão organizacional: um estudo de caso numa empresa metal-mecânica. In: CONGRESSO VIRTUAL BRASILEIRO DE ADMINISTRAÇÃO, 8. Anais. São Paulo: 2011.

AGUIAR, A. B.; CORRAR, L. J.; BATISTELLA, F. D.. Adoção de práticas de governança corporativa das ações na Bovespa: evidências empíricas. Revista de Administração da USP, v.39, n.4, p.338-347, 2004.

AGUILERA, R. V.; JUIZ, W. Q.; TERJESEN, S. A.. Desvio de governança corporativa. Academy of Management Review, v.43, n.1, p.87-109, 2018.

ALVARES, E.; GIACOMETTI, C.; GUSSO, E. Governança corporativa: um modelo brasileiro. Rio de Janeiro: Elsevier, 2008.

AMIR, E.; LEV, B.. Value-relevance of nonfinancial information: The wireless communications industry. Journal of accounting and economics, v.22, n.3, p.3-30, 1996.

ANDRADE, A.; ROSSETTI, J. P.. Governança corporativa: fundamentos, desenvolvimento e tendências. In Governança corporativa: fundamentos, desenvolvimento e tendências. São Paulo: Atlas, 2004.

BARNEY, J. B.; HESTERLY, W.. Economia das organizações: entendendo a relação entre as organizações e a análise econômica. Handbook de Estudos organizacionais, São Paulo, v.3, p.131-179, 2004.

BEINER, S.; DROBETZ, W.; SCHMID, F.; ZIMMERMANN, H.. IS board size an independent corporate governance mechanism?. Kyklos, v.57, n.3, p.327-356, 2004.

BLACK, B. S.; JANG, H.; KIM, W.. Does corporate governance affect firm value?: evidence from Korea. Chicago: University of Chicago Law School, 2003.

CASELANI, D. M.; CASELANI, C. N.. A Geração de valor em companhias brasileiras através da utilização de direcionadores financeiros e não-financeiros. In: ENCONTRO DA ASSOCIAÇÃO NACIONAL DE PÓS-GRADUAÇÃO EM ADMINISTRAÇÃO, 30. Anais. Salvador: 2005.

FRANCISCO, J. R. S.. Índice de governança corporativa: criação de valor e desempenho nas cooperativas de crédito. Belo Horizonte: UFMG, 2014.

IBGC. Instituto Brasileiro De Governança Corporativa. Código das melhores práticas de governança corporativa. São Paulo: IBGC, 2017.
ITTNER, C. D.; LARCKER, D. F.. Innovations in performance measurement: Trends and research implications. Journal of management accounting research, v.10, p.205, 1998.

JENSEN, M. C.; MECKLING, W. H.. Theory of the firm: Managerial behavior, agency costs and ownership structure. Journal of financial economics, v.3, n.4, p.305360, 1976.

KRISHNAKUMAR, J.; NAGAR, A. L.. On exact statistical properties of multidimensional indices based on principal components, factor analysis, MIMIC and structural equation models. Social Indicators Research, v.86, n.3, p.481-496, 2008.

LOW, J.; SIESFELD, T.. Measures that matter: Non-financial performance. Strategy \& Leadership, v.26, n.2, p.24-38, 1998.

MACMILLAN, H.; TAMPOE, M.. Strategic management: process, content, and implementation. Oxford: Oxford University Press, 2001.

MANLY, B. F. J.. Multivariate Statistical Methods. New York: Chapman and Hall, 1986.

MINGOTI, S. A.. Análise de dados através de métodos de estatística multivariada: uma abordagem aplicada. Belo Horizonte: EDUFMG, 2005.

MOURA, G. D.; VARELA, P. S.. Análise Das Práticas De Governança Corporativa De Companhias Abertas Listadas $\mathrm{Na}$ Bm\&Fbovespa. Revista de Governança Corporativa, v.3, n.2, p.1-26, 2016.

NAGAR, A. L.; BASU, S. R.. Weighting socioeconomic indicators of human development: A latent variable approach. Statistics Textbooks and MonographS, v.165, p.609-642, 2002.

PACE, E. S. U.; BASSO, L. F. C.; SILVA, M. A. D.. Indicadores de desempenho como direcionadores de valor. Revista de Administração Contemporânea, v.7, n.1, p.37-65, 2003.

SANTANA, A. C.; SANTANA, Á. L.; SANTANA, Á. L.; COSTA, N. L.; NOGUEIRA, A. K. M. Planejamento Estratégico de uma Universidade Federal na Amazônia: Aplicação da Análise Fatorial. Revista de Estudos Sociais, v.16, n.32, p.183-204, 2014.

STEINBERG, H.. A dimensão humana da governança corporativa: pessoas criam as melhores e as piores práticas. São Paulo: Gente. 2003.

WOOD JUNIOR, T.. Mudança organizacional: aprofundando temas atuais em administração de empresas. São Paulo: Atlas, 1995.

A CBPC - Companhia Brasileira de Produção Científica (CNPJ: 11.221.422/0001-03) detém os direitos materiais desta publicação. Os direitos referem-se à publicação do trabalho em qualquer parte do mundo, incluindo os direitos às renovações, expansões e disseminações da contribuição, bem como outros direitos subsidiários. Todos os trabalhos publicados eletronicamente poderão posteriormente ser publicados em coletâneas impressas sob coordenação da Sustenere Publishing, da Companhia Brasileira de Produção Científica e seus parceiros autorizados. Os (as) autores (as) preservam os direitos autorais, mas não têm permissão para a publicação da contribuição em outro meio, impresso ou digital, em português ou em tradução. 